https://helda.helsinki.fi

\title{
The effect of CPAP treatment for obstructive sleep apnea on asthma control-study limitations-author's response
}

\section{Kauppi, Paula}

2016-12

Kauppi , P , Bachour , P , Maasilta , P \& Bachour , A 2016, ' The effect of CPAP treatment for obstructive sleep apnea on asthma control-study limitations-author's response ', Sleep and Breathing , vol. 20 , no. 4 , pp. 1271-1272 . https://doi.org/10.1007/s11325-016-1386-0

http://hdl.handle.net/10138/230305

https://doi.org/10.1007/s11325-016-1386-0

publishedVersion

Downloaded from Helda, University of Helsinki institutional repository.

This is an electronic reprint of the original article.

This reprint may differ from the original in pagination and typographic detail.

Please cite the original version. 


\title{
The effect of CPAP treatment for obstructive sleep apnea on asthma control—study limitations—author's response
}

\author{
Paula Kauppi $^{1} \cdot$ Patrick Bachour $^{2} \cdot$ Paula Maasilta $^{2} \cdot$ Adel Bachour $^{2}$
}

Received: 6 June 2016 /Revised: 5 July 2016 / Accepted: 12 July 2016 / Published online: 20 July 2016

(C) Springer-Verlag Berlin Heidelberg 2016

Dear Editor,

We thank colleagues Dr. Cravo, Dr. Pazarli, and Dr. Esquinas for their interest in our study and their comments. First, we agree that polygraphy has lower sensitivity than polysomnography (PSG) especially in cases with a lower respiratory event index (REI) [1]. The mean REI in our study was 41 ; therefore, we do not believe that cases of false negative OSA were included in our study population. Second, none of the patients included in the study had obesity hypoventilation syndrome and, thus, we focused on CPAP treatment [3]. Third, we have discussed in our paper that the retrospective study design is one of the study limitations and, indeed, includes the possibility of recall bias [2]. Finally, the medication of the patients was analyzed by self-reported use of rescue medication which is one the questions included in the asthma control test (ACT). However, as we have discussed in our paper, further analyses of asthma medication would also include the possibility of bias since use of medication is reported by patients.

Using information in medical records is a commonly employed technique in clinical studies. Unfortunately, patients often use their drugs (both tablets and inhalers) in a different way than they are prescribed and, thus, even medical record information on prescribed drugs is only an estimation [4].

Paula Kauppi

paula.kauppi@hus.fi

Inflammation Centre, Skin and Allergy Hospital, Helsinki University Hospital, University of Helsinki, P.O. Box 160, 00029 Helsinki, Finland

2 Sleep Unit, Heart and Lung Centre, Helsinki University Hospital, University of Helsinki, Meilahdentie 2, P.O. Box 160, HUS, 00029 Helsinki, Finland
Considering the concept of different phenotypes of asthma and results from other studies on CPAP treatment, we find it likely that CPAP is mostly beneficial for patients with both OSA and asthma.

We believe that the benefit of CPAP on asthma is related to its effect on improving the acinar ventilation heterogeneity as well as reducing reflux. However, an important effect involves abolishing respiratory disturbances since we found similar results with the use of mandibular advancement devices [5]. A prospective study including sleep apnea patients, asthma patients, and patients with both disorders in a study design that includes PSG, lung function, inflammatory parameters, self-reported symptoms, medication and adherence to medication, and CPAP use would give further objective information on this issue.

Thus, our real-life study results are important and valuable but need to be read with caution in view of the study limitations as outlined in our paper.

\section{Compliance with ethical standard}

Informed consent Informed consent was obtained from all individual participants included in the study.

\section{References}

1. Collop NA, Tracy SL, Kapur V, Mehra R, Kuhlmann D, Fleishman SA, Ojile JM (2011) Obstructive sleep apnea divices for out-of-center (OOC) testing: technology evaluation. J Clin Sleep Med 7:531-548

2. Kauppi P, Bachour P, Maasilta P, Bachour, A (2016). Long-term CPAP treatment improves asthma control in patients with asthma and obstructive sleep apnea. Sleep Breath. 2016 Apr 7. [Epub ahead of print]. 
3. Mokhlesi B, Kryger MH, Grunstein RR (2008) Assessment and management of patients with obesity hypoventilation syndrome. Proc Am Thorac Soc 5:218-225

4. Gutièrrez SJ, Fagnano M, Wiesenthal E, Koehler AD, Halterman JS (2014) Discrepancies between medical record data and parent reported use of preventive asthma medications. J Asthma 51:446450. doi:10.3109/02770903.2013.878351.

5. Bachour P, Bachour A, Kauppi P, Maasilta P, Mäkitie A, Palotie T (2016) Oral appliance in sleep apnea treatment: respiratory and clinical effects and long-term adherence. Sleep Breath 20:805-812 